\title{
El Arte... motor de la Ciencia. Ciencia, Técnica y Arte
}

\author{
Salgado, Cristina R. \\ ${ }^{1}$ Dra. de la UNNE en Recursos Naturales. Docente de la FCA-UNNE. Responsable Técnico del \\ Servicio de Microscopia Electrónica - SGCyT de la Universidad Nacional del Nordeste
}

Conferencia dictada la apertura de AgroArte 2017, en el marco de la XI Reunión Nacional Científico-

Técnica de Biología de Suelos. Corrientes (Argentina)- Octubre de 2017.

\section{RESUMEN}

A través de la historia de la Humanidad, el Arte, la Ciencia y la Tecnología se desarrollaron y fueron evolucionando en forma conjunta y convergiendo en muchos aspectos. El Arte o las expresiones artísticas surgen de lo instintivo, de la necesidad humana de expresarse. La Técnica responde a habilidades adquiridas, generalmente por ensayo y error, de esta manera vamos incorporando habilidades y aprendiendo a partir de la relación causa-efecto. La Ciencia, más reflexiva, parte de la observación, la formulación de hipótesis, la comprobación de los hechos y finalmente, de la aplicación práctica de los conocimientos científicos surge la Tecnología.

El hombre ha logrado conjugar el arte, la ciencia y la tecnología, un ejemplo destacable son los Mayas excelentes matemáticos, astrónomos y constructores. En la península de Yucatán (México) en la ciudad Chichén - Itzá, usaron la piedra caliza para construir la Pirámide de Kukulkán, deidad con forma de serpiente a la que realizaban sacrificios humanos para solicitar favores. Durante el equinoccio de primavera, el Sol, en un fascinante juego de luces y sombras, proyecta sobre los laterales de las escalinatas la silueta ondulante de una serpiente.

La posibilidad de dominar distintos materiales, como la madera, la piedra o los metales permitió numerosos descubrimientos. En este sentido, los alquimistas han sido sin dudas los primeros científicos. La Alquimia es

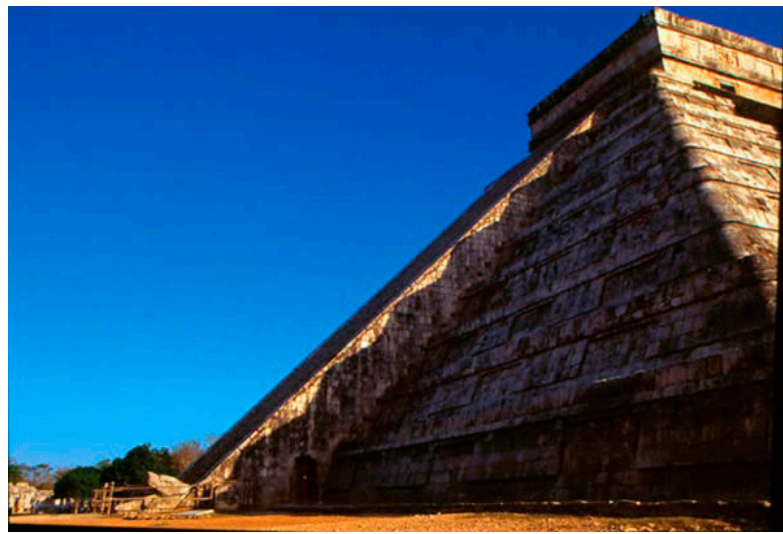

Figura 1. Imagen del Templo de Kukulkán construido en el siglo XII d.C. en la ciudad prehispánica de Chichén Itzá. una antigua práctica protocientífica y disciplina filosófica que combina elementos de la química, metalurgia, física, medicina, astrología, misticismo y arte. El alquimista Alberto Magno (siglo XIII) documentó la capacidad del ácido nítrico para separar el oro y la plata por disolución de esta última, observó que la solución resultante: nitrato de plata podía oscurecer la piel. Este compuesto tiene propiedades antisépticas y desinfectantes.

Existieron personas extraordinarias en las que se conjugaron muchas habilidades, el gran Leonardo Da Vinci fue: pintor, anatomista, arquitecto, paleontólogo, botánico, filosofo, ingeniero, inventor... Como resultado de numerosas observaciones, realizó el dibujo conocido como "El Hombre de Vitruvio" que ilustra las proporciones ideales del cuerpo humano, por ejemplo: la longitud de la mano es $1 / 10$ de la altura de una persona; la distancia de un hombro al otro es $1 / 4$ de la altura y la longitud desde el mentón hasta donde termina la cabeza es $1 / 8$ de la altura.

El cuerpo humano fue inspiración de muchos artistas y motivo para el desarrollo de numerosos estudios científicos. Argentina se enorgullece de contar con destacados investigadores cuyos descubrimientos han constituido un inestimable aporte a la Humanidad y les han valido meritorios Premios Nobel en Fisiología, Medicina y Química. Bernardo A. Houssay (1887-1971) en 1947 con su descubrimiento de la función hormonal de la glándula pituitaria en el metabolismo. Luis $\boldsymbol{F}$. Leloir (1906-1987) en 1970 con su descubrimiento de los nucleótidos y su función en la biosíntesis de hidratos de carbono. Y Cesar Milstein (1927-2002) en 1984, desarrolló la técnica para la producción de anticuerpos monoclonales. Estos tres científicos argentinos no pintaron cuadros ni tallaron la piedra, pero sin dudas tenían las cualidades que todo buen artista posee: pasión, humildad y generosidad.

Houssay supervisó el doctorado de Leloir, recibió 80.000 dólares por su Premio Nobel y los donó a la ciencia. Milstein no patentó sus descubrimientos, pues consideraba que su trabajo era un legado para la humanidad. Houssay tenía una fuerte convicción respecto al rol social del científico. Sostenía que los becarios podían estudiar gracias a los recursos aportados por todos los compatriotas, por lo tanto debían retribuirles trabajando 
aquí y contribuir con su país. Houssay fue el refundador del CONICET y su Director.

Siempre habrá nuevas herramientas o instrumentos tecnológicos, tanto para el artista como para el espectador que permitan crear o mostrar la belleza en lo cotidiano, en las cosas simples que nos rodean y no vemos a simple vista. En este sentido, la Informática ha colaborado enormemente con el Arte, la Ciencia y la Técnica, permitiendo realizar efectos visuales. Un ejemplo de esto es la muestra expuesta en el museo de la Universidad Nacional de Tucumán, donde investigadores tomaron muestras de la superficie de una escultura y luego cultivaron los microorganismos presentes en ella. Luego, con la técnica de "mapping" proyectaron las imágenes de bacterias, hongos y pequeños arácnidos tomadas con un microscopio electrónico de barrido sobre la escultura.

La UNNE también cuenta con un microscopio electrónico de barrido JEOL 5800LV que asiste a los investigadores de las distintas unidades académicas de nuestra Universidad y al de otras Universidades de la Región como UNaM, UNaF, UNCAus, institutos del CONICET, etc. Y todo aquel que requiera el servicio ya que estamos abiertos a la comunidad. Fue adquirido en el año 1997 y puesto en funcionamiento en 1998.

En el año 2006 el Dr. Jorge Avanza, Secretario General de Ciencia y Técnica de ese momento, solicitó a los técnicos del Servicio de Microscopia Electrónica la organización de una muestra de Arte Científico. La misma estaba formada por 30 obras de los investigadores que utilizaban el equipo. Hoy, esos cuadros adornan las paredes del Servicio de ME de Barrido de la UNNE. Recientemente, la Sociedad Argentina de Nanotecnología ha premiado una fotografía denominada "Helios" tomada en el mencionado Servicio de la UNNE en el marco del V Concurso Nacional de Fotografía Científica y Tecnológica organizado por el MINCyT. Premio que motivó a los organizadores de AgroArte 2017 a realizar una conferencia orientada a hablar de la relación de la Ciencia y el Arte.

Los nuevos artistas son los nanotecnológos, pueden crear esculturas tan pequeñas como un grano de arena en una fracción del tiempo que se requería previamente, lo que supone un récord mundial de velocidad en nanotecnología. No es solo una curiosidad científica, sus avances pueden ser utilizados en campos como la medicina, para crear diminutos instrumentales de cirugía.

Jonty Hurwitz, artista afincado en Londres, se ha valido de la impresión 3D para crear nanoesculturas de 20 micras, son tan infinitesimales que sólo pueden observarse mediante un microscopio electrónico de barrido. Para demostrar su microtamaño, el artista ha recurrido a diferentes recursos, por ejemplo situar sus diminutas esculturas sobre un cabello o colocarlas en el ojo de una aguja. "El desafío es que existen estas obras más allá de los límites de nuestras capacidades de percepción, y como consecuencia más allá de los reinos de lo que

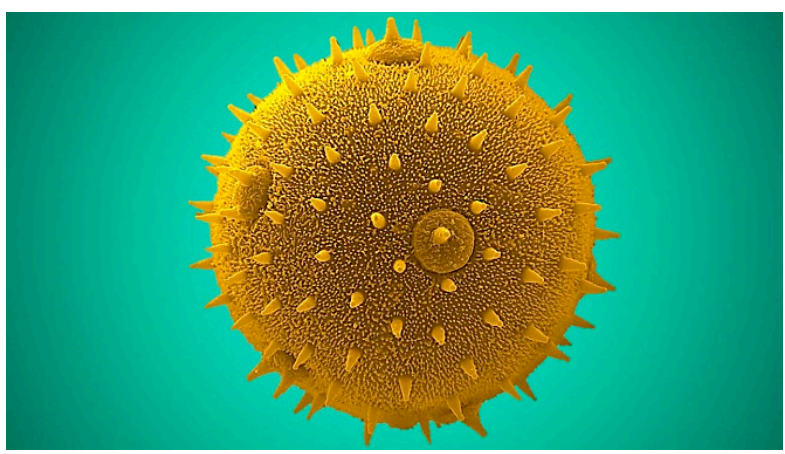

Figura 2. Grano de polen de Cucurbita maxima (n/v zapallo), imagen premiada por la Sociedad Argentina de Nanotecnología (Ciencia en Foco 2017).

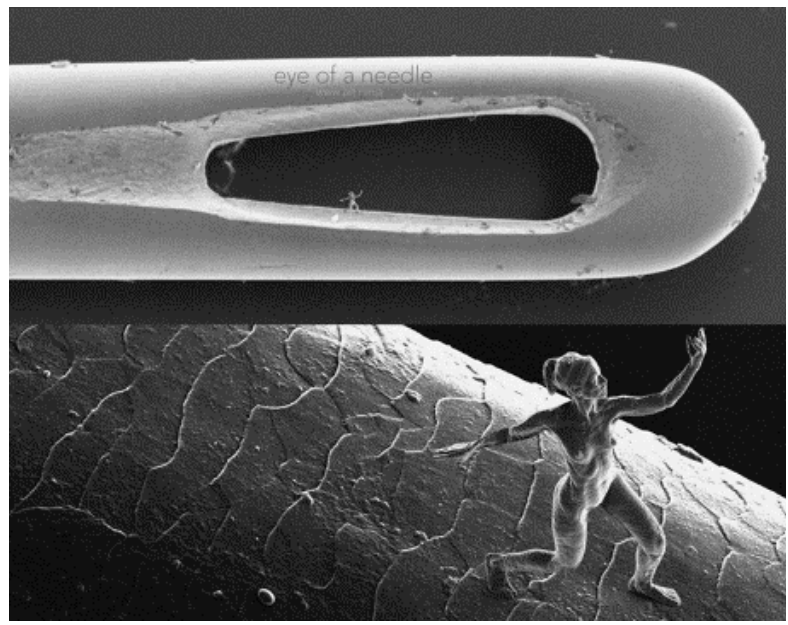

Figura 3. Nanoescutruras ubicadas en el ojo de una aguja y sobre un cabello humano, observadas con microscopio electrónico de barrido.

podemos visualizar", dijo Hurwitz y añadió "El espesor de un cabello es algo sobre lo que cada persona ha reflexionado en algún momento de su infancia".

Finalmente, desde los soñadores Alquimistas hasta los fanáticos Nanotecnólogos, pasando por los artistas Renacentistas, han logrado poner de manifiesto puntos en común entre Ciencia, Arte y Técnica generando obras maestras. Todas las personas vinculadas a la Ciencia contribuyen con su grano de arena al conocimiento, con la docencia lo transmiten al joven y deben hacerlo con la pasión de un artista.

Seamos como describe el genial Eduardo Galeano.

... «Y dijo que somos un mar de fueguitos. -El mundo es eso -reveló- un montón de gente, un mar de fueguitos. Cada persona brilla con luz propia entre todas las demás».

«No hay dos fuegos iguales. Hay fuegos grandes y fuegos chicos y fuegos de todos los colores. Hay gente de fuego sereno, que ni se entera del viento, y gente de fuego loco que llena el aire de chispas».

Algunos fuegos, fuegos bobos, no alumbran ni queman; pero otros arden la vida con tanta pasión que no se puede mirarlos sin parpadear, y quien se acerca se enciende... » Extracto de "Un mar de fueguitos". 